\title{
Pediatric NIV Pressure Injury: Honing the Cause and Progress to Solutions
}

Like adults, pediatric patients are at risk for pressure injury due to reduced perfusion, mobility, neurological response, and increased moisture, with additional risk due to underdeveloped skin in neonates. ${ }^{1}$ Institutional health care goals of improving health care outcomes, patient safety and quality, meeting higher certification standards, and reducing costs have prompted focus on the early detection, reduced severity, and prevention of pressure injuries. ${ }^{2,3}$ Pressure injuries in pediatric subjects 1-4 y old were associated with increased stay by 14 days and costs by $\$ 86,000$ compared to age-matched subjects without injury. ${ }^{4}$

The incidence of pediatric pressure injury has been reported to be $1-8 \%$ overall and up to $43 \%$ in critical care units. ${ }^{5}$ Medical devices, including face masks for noninvasive ventilation (NIV), account for 38.5-90\% of injuries in neonates and young children.6,7 Although pressure injuries are acute, injuries from NIV can result in problematic, longer-term deformities. ${ }^{8}$ However, NIV is effective for respiratory failure because it reduces the rates of endotracheal intubation and re-intubation. ${ }^{9}$

Rates of pressure injuries from NIV masks have been reported to be as high as $30 \%$ in adult patients. ${ }^{10}$ In a comparative study, the occurrence of pressure injuries for nasal-oral masks was $20 \%$ versus $2 \%$ for total face masks among 2 groups of adults age $61 \pm 15 \mathrm{y} .{ }^{11}$ The times to pressure injury were $28.4 \mathrm{~h}$ and $61.4 \mathrm{~h}$ for nasal-oral versus total face masks, respectively. Face mask-related pressure injuries can occur at the nasal bridge, cheeks, chin, and forehead. Figure 1 shows an example stage II pressure injuries at the nasal bridge and forehead from a nasal mask in a young patient. Figure 2 shows the results of a 3-dimensional surface-scanning technique to measure mask fit on the same subject. ${ }^{12}$ The mean distance from the face to the mask was $7.2 \mathrm{~mm}$; positive values indicate the mask to be pressing into the skin. Distances in red are the highest (at cheeks). The mask was not touching the face at the upper cheek (right side of image) near the bridge of the nose.

Dr Visscher has disclosed no conflicts of interest.

Correspondence: Marty O Visscher PhD, The James L. Winkle College of Pharmacy, 3255 Eden Avenue 45267 \#161, University of Cincinnati, Cincinnati, OH. E-mail: visschmo@ucmail.uc.edu.

DOI: $10.4187 /$ respcare. 07520

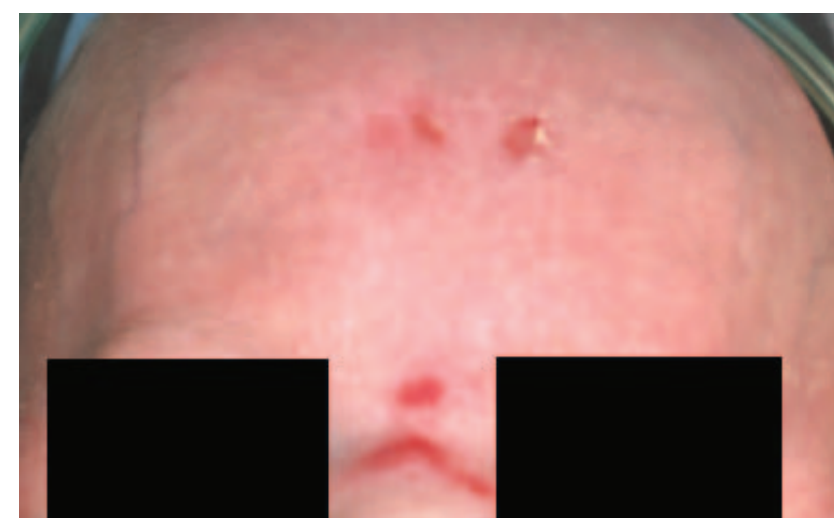

Fig. 1. Example of stage II pressure injuries at the nasal bridge and forehead from a nasal mask in a young patient.

More recently, 3-dimensional surface scanning and 3-dimensional printing have been used to create customized face masks. A randomized crossover trial among healthy adults tested the concept and reported that such masks have the potential to reduce the incidence and severity of pressure injuries and to improve comfort. ${ }^{13}$ Advances in monitoring systems have facilitated the determination of mask/skin interface pressures, showing higher pressures at the nose bridge versus the cheeks and higher pressures

See the Original Study on Page 1455

with increasing strap tension. ${ }^{14}$ At the time of the highest strap tension, mask interface points contained increasing levels of interleukin $1 \alpha$, a cytokine biomarker of inflammation, which was measured from sebum collected from the skin surface. Measures of transepidermal water loss in combination with cytokine assessment indicated that humidification with CPAP ventilation compromised the skin integrity relative to no humidification. ${ }^{15}$

Lauderbaugh et al ${ }^{16}$ report important, multifactorial research results on the factors associated with pressure injury in pediatric subjects using NIV devices. Their comprehensive examination not only provides new information about the multiple potential contributors to injury but will focus efforts and practices to reduce the incidence and severity. This work also provides an investigative strategy and statistical approach that can serve as a benchmark for future investigations. Fur- 


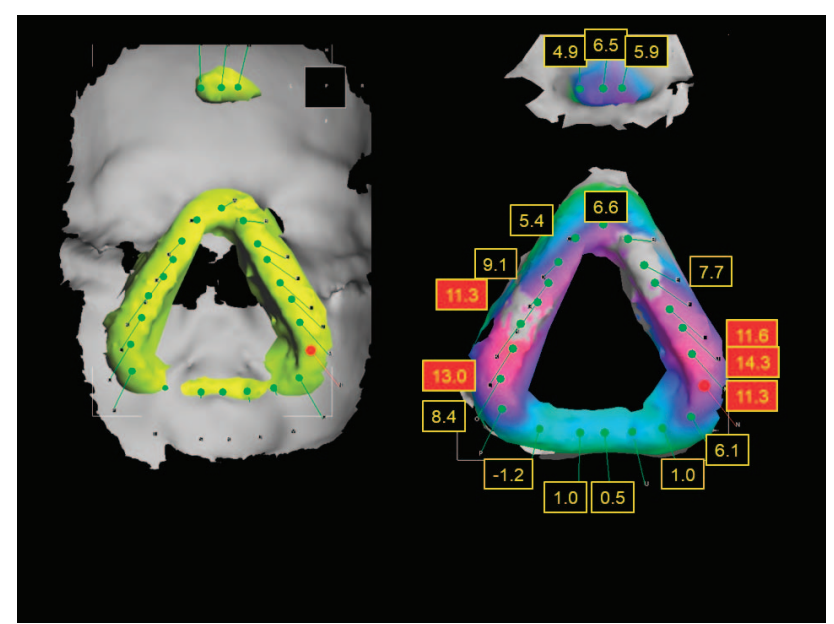

Fig. 2. Results of a 3-dimensional surface-scanning technique to measure mask fit on the same subject.

ther, their information and findings help fill gaps in the available literature regarding pediatric pressure injuries.

Lauderbaugh et al ${ }^{16}$ retrospectively evaluated pressure injuries due to NIV in a large sample size ( $N=255$ subjects, no. $=343$ episodes $)$ of pediatric subjects over a wide range of ages (2 months to $35 \mathrm{y}$ ). They found an incidence of $7.3 \%$ and comprehensively queried causative factors using multivariate logistic statistical methods. They are the first to report that high mask leak was the sole factor that was significantly associated with pressure injury. The nonsignificant factors were maximum inspiratory positive air pressure, log of time on NIV, maximum mask leak, use of more than one mask/ mask type, older age, time to skin erythema, and Braden Q score. Sixty-four percent of pressure injuries were stage I. These results reinforce the relatively rapid onset of skin compromise with visible but blanchable redness occurring by $1.8 \pm 2.3 \mathrm{~d}$ of mask use for half of the subjects and pressure injury by day $3.7 \pm 2.7$. Consistent with previous reports, the majority of pressure injuries were at the nasal bridge.

The findings of Lauderbaugh et al ${ }^{16}$ clearly inform practice. Importantly, future efforts should focus on strategies and interventions, including mask/equipment modifications, to reduce leak. It is recommended that new approaches be studied among complex patients because further reduction in pressure injury among such patients will likely translate across users of NIV.

Marty O Visscher

Skin Pharmaceutics and Cosmetic Science The James L. Winkle College of Pharmacy University of Cincinnati Cincinnati, Ohio

\section{REFERENCES}

1. Schindler CA, Mikhailov TA, Fischer K, Lukasiewicz G, Kuhn EM, Duncan L. Skin integrity in critically ill and injured children. Am J Crit Care 2007;16(6):568-574.

2. Centers for Medicare and Medicaid Services (CMS), HHS. Medicaid program; payment adjustment for provider-preventable conditions including health care-acquired conditions. Final rule. Fed Regist 2011;76(108):32816-32838.

3. Visscher M, King A, Nie AM, Schaffer P, Taylor T, Pruitt D, et al. A quality-improvement collaborative project to reduce pressure ulcers in PICUs. Pediatrics 2013;131(6):e1950-e1960.

4. Goudie A, Dynan L, Brady PW, Fieldston E, Brilli RJ, Walsh KE. Costs of venous thromboembolism, catheter-associated urinary tract infection, and pressure ulcer. Pediatrics 2015;136(3):432-439.

5. Delmore B, Deppisch M, Sylvia C, Luna-Anderson C, Nie AM. Pressure injuries in the pediatric population: a national pressure ulcer advisory panel white paper. Adv Skin Wound Care 2019;32(9):394408.

6. Schlüer AB, Halfens RJ, Schols JM. Pediatric pressure ulcer prevalence: a multicenter, cross-sectional, point prevalence study in Switzerland. Ostomy Wound Manage 2012;58(7):18-31.

7. Visscher M, Taylor T. Pressure ulcers in the hospitalized neonate: rates and risk factors. Sci Rep 2014;4:7429.

8. Khan J, Sundaram V, Murki S, Bhatti A, Saini SS, Kumar P. Nasal injury and comfort with jet versus bubble continuous positive airway pressure delivery systems in preterm infants with respiratory distress. Eur J Pediatr 2017;176(12):1629-1635.

9. Yaman A, Kendirli T, Ödek Ç, Ateş C, Taşyapar N, Güneş M, İnce E. Efficacy of noninvasive mechanical ventilation in prevention of intubation and reintubation in the pediatric intensive care unit. J Crit Care 2016;32:175-181.

10. Conti G, Marino P, Cogliati A, Dell'Utri D, Lappa A, Rosa G, Gasparetto A. Noninvasive ventilation for the treatment of acute respiratory failure in patients with hematologic malignancies: a pilot study. Intensive Care Med 1998;24(12):1283-1288.

11. Schallom M, Cracchiolo L, Falker A, Foster J, Hager J, Morehouse $\mathrm{T}$, et al. Pressure ulcer incidence in patients wearing nasal-oral versus full-face noninvasive ventilation masks. Am J Crit Care 2015; 24(4):349-356.

12. Visscher MO, White CC, Jones JM, Cahill T, Jones DC, Pan BS. Face masks for noninvasive ventilation: fit, excess skin hydration, and pressure ulcers. Respir Care 2015;60(11):1536-1547.

13. Shikama M, Nakagami G, Noguchi H, Mori T, Sanada H. Development of personalized fitting device with 3-dimensional solution for prevention of NIV oronasal mask-related pressure ulcers. Respir Care 2018;63(8):1024-1032.

14. Worsley PR, Prudden G, Gower G, Bader DL. Investigating the effects of strap tension during non-invasive ventilation mask application: a combined biomechanical and biomarker approach. Med Devices (Auckl) 2016;9:409-417.

15. Alqahtani JS, Worsley P, Voegeli D. Effect of humidified noninvasive ventilation on the development of facial skin breakdown. Respir Care 2018;63(9):1102-1110.

16. Lauderbaugh DL, Bhattacharjee R, Proudfoot J, Ortega EV, Pratt LA, Popien T, Lesser DJ. Noninvasive ventilation device-related pressure injury in a children's hospital. Respir Care 2019;64(12): $1455-1460$ 